\title{
Therapeutic response to a novel enzyme-targeting radiosensitization treatment (Kochi Oxydol-Radiation Therapy for Unresectable Carcinomas) in patients with recurrent breast cancer
}

\author{
NOBUTAKA AOYAMA $^{1}$, YASUHIRO OGAWA ${ }^{2}$, MIKI YASUOKA ${ }^{1}$, MASAO TAKAHASHI ${ }^{1}$, \\ HITOMI IWASA ${ }^{1}$, KANA MIYATAKE ${ }^{1}$, TOMOAKI YAMANISHI ${ }^{1}$, NORIHIKO HAMADA ${ }^{1}$, \\ TAIJI TAMURA ${ }^{1}$, AKIHITO NISHIOKA $^{1}$ and TAKUJI YAMAGAMI ${ }^{1}$ \\ ${ }^{1}$ Department of Diagnostic Radiology and Radiation Oncology, Medical School, Kochi University, \\ Kochi 783-8505; ${ }^{2}$ Hyogo Prefectural Kakogawa Medical Center, Hyogo 675-8555, Japan
}

Received February 6, 2015; Accepted March 1, 2016

DOI: $10.3892 / \mathrm{ol} .2016 .4589$

\begin{abstract}
Linear accelerator-based radiotherapy has little effect on the majority of locally advanced neoplasms. Thus, the novel radiosensitizer Kochi Oxydol Radiation Therapy for Unresectable Carcinomas, Type II (KORTUC II), which contains hydrogen peroxide and sodium hyaluronate, was developed. The effectiveness of KORTUC II for the treatment of chemotherapy-resistant supraclavicular lymph node metastases has been previously demonstrated. The present study evaluated the safety and effectiveness of KORTUC II in patients with recurrent breast cancer. A total of 20 patients (age range, 39-84 years) were enrolled in the study. The majority of patients underwent positron emission tomography (PET)-computed tomography (CT) examinations prior to and 1-7 months following KORTUC II treatment, and every 6 months thereafter when possible. The radiotherapy regimen was $2.75 \mathrm{~Gy} /$ fraction, 5 fractions/week, for 16-18 fractions, with a total radiation dose of 44.00-49.50 Gy (X-ray irradiation), or $4.00 \mathrm{~Gy} /$ fraction, 3 fractions/week, for 10-12 fractions, with a total radiation dose of 40.00-48.00 Gy (electron beam irradiation). The injection of 3-6 $\mathrm{ml}$ of the KORTUC II agent was initiated at the fifth radiotherapy fraction, and was performed twice/week under ultrasonographic guidance. The therapeutic effects were evaluated by PET-CT examinations prior and subsequent to KORTUC II treatment, which was observed to be well tolerated with minimal adverse effects. Of the 24 lesions presented by the 20 patients, 18 exhibited complete response, 5 partial response, 0 stable disease and
\end{abstract}

Correspondence to: Dr Nobutaka Aoyama, Department of Diagnostic Radiology and Radiation Oncology, Medical School, Kochi University, Oko-cho, Nankoku-shi, Kochi 783-8505, Japan E-mail: jm-aoyama_nobutaka@kochi-u.ac.jp

Key words: hydrogen peroxide, KORTUC II, radiosensitizer, recurrent breast cancer, sodium hyaluronate, ultrasonographic guidance
1 progressive disease. The overall survival rate was $100 \%$ at 1 year and $95 \%$ at 2 years. The mean duration of follow-up at the end of June 2014 was 51 months. Based on the results of the PET-CT studies conducted, KORTUC II treatment demonstrated marked therapeutic effects, with satisfactory treatment outcomes and acceptable adverse events.

\section{Introduction}

Radiotherapy is considered to be a good therapeutic strategy for the local treatment of tumors (1-3). Due to the improvement in diagnostic methods, the use of radiotherapy for the treatment of recurrent malignancies and/or distant metastases that are limited to a single site/organ (oligometastasis) has increased in recent years (1-3). However, the use of radiotherapy presents a number of disadvantages (4-8). In radiotherapy, a linear accelerator generates high-energy X-rays and electron beams that are generally used for tumor treatment (4-8). However, these are low-linear energy transfer (LET) forms of radiation, and thus exert relatively weak biological effects on tumors that contain numerous hypoxic cancer cells and/or large quantities of antioxidative enzymes (4-8), including malignant melanoma, various types of sarcoma, glioblastoma multiforme and the majority of tumors that measure more than several centimeters in their long diameter (4-8). Previous studies have examined the efficacy of increasing tissue oxygen concentration to promote the oxidation of radicals produced by low-LET irradiation to cancer cells/tissue, but limited therapeutic advantages have been observed thus far (9-20). In addition to increasing the tissue oxygen concentration, it is important to inactivate antioxidative enzymes such as peroxidase and catalase, which protect cancer cells from oxidative stress (4-8). Kochi Oxydol-Radiation Therapy for Unresectable Carcinomas, Type II (KORTUC II) was developed for the treatment of malignant tumors that contain numerous hypoxic cancer cells and/or large quantities of antioxidative enzymes (4-8). The concepts underlying this novel enzyme-targeting radiosensitization treatment are represented in Fig. 1. Hydrogen peroxide is the only agent known to be capable of inactivating antioxidative enzymes and producing oxygen when applied topically to tumor tissues (4-8). 
In a previous report, the effectiveness of KORTUC II for the treatment of supraclavicular lymph node metastases was demonstrated (7). The purpose of the present study was to evaluate the safety and effectiveness of KORTUC II in patients with recurrent breast cancer.

\section{Materials and methods}

Patients. The present study was performed from February 2006 to June 2014. The institutional ethics committee of Kochi University (Kochi, Japan) approved the use of KORTUC II in combination with radiation therapy for the treatment of recurrent breast cancer. A total of 20 patients with recurrent breast cancer were enrolled in the present study upon providing written informed consent. All patients underwent complete surgical removal of the primary breast cancer, but recurrent breast cancer was observed during the follow-up examination by positron emission tomography (PET)-computed tomography (CT) (Discovery STE; GE Healthcare, Tokyo, Japan). The details of the recurrent lesions are shown in Table I. Patients' age ranged from 39.0 to 84.0 years (average, 66.4 years). The majority of patients underwent neoadjuvant chemotherapy. The most frequent chemotherapy regimens administered prior to radiosensitization treatment were adriamycin (Kyowa Hakko Kirin Co., Ltd., Tokyo, Japan) + cyclophosphamide (CPA; Shionogi \& Co., Ltd., Osaka, Japan) + 5-fluorouracil (5-FU; Kyowa Hakko Kirin Co., Ltd.), CPA + docetaxel (Elmed Eisai Co., Ltd., Tokyo, Japan), CPA + epirubicin (EPI; Nippon Kayaku, Tokyo, Japan), CPA + 5-FU + methotrexate (Pfizer Inc., New York, NY, USA), CPA + 5-FU + tetrahydropalmatine (Daiichi Sankyo Healthcare Co., Ltd, Tokyo, Japan), EPI + 5-FU, gemcitabine (Yakuruto Co., Ltd., Tokyo, Japan) + herceptin (HER; Chugai Pharmaceutical Co., Ltd., Tokyo, Japan), HER + paclitaxel (PTX; Nippon Kayaku), HER + vinorelbine (Kyowa Hakko Kirin Co., Ltd.) and PTX. All chemotherapies were administered every 3 weeks.

However, since the sizes of the tumors were not conspicuously reduced, the patients were diagnosed as being resistant to these chemotherapies. Therefore, it was decided to use the novel radiosensitizer KORTUC II. The basic criterion for case selection was that the patients and/or their family wanted the patient to receive KORTUC II treatment and did not wish the patient to undergo surgery. In addition, further criteria included the absence of metastases to brain, lung or liver, and life expectancy $>3$ months.

Radiation therapy to recurrent breast cancer consisted of $2.75 \mathrm{~Gy} /$ fraction, 5 fractions/week, for a total of 16-18 fractions, with a total radiation dose of 44.00-49.50 Gy (X-ray irradiation), or $4.00 \mathrm{~Gy} /$ fraction, 3 fractions/week, for a total of 10-12 fractions, with a total radiation dose of 40.00-48.00 Gy (electron beam irradiation; EXL-20TP linear accelerator; Mitsubishi Electric Co., Ltd., Tokyo, Japan). Electron beam irradiation was performed for patients who had received postoperative irradiation $(2.75 \mathrm{~Gy} /$ fraction, 16 times, total $44.00 \mathrm{~Gy})$ at the treatment site of the primary breast cancer, or in those cases where the recurrence involved superficial lesions. In the case of X-ray irradiation for patients with locally recurrent lesions who did not receive postoperative radiotherapy following the treatment of the primary breast cancer, boost irradiation (3 Gy/fraction, 3 times) was added. For locally recurrent lesions, tangential irradiation

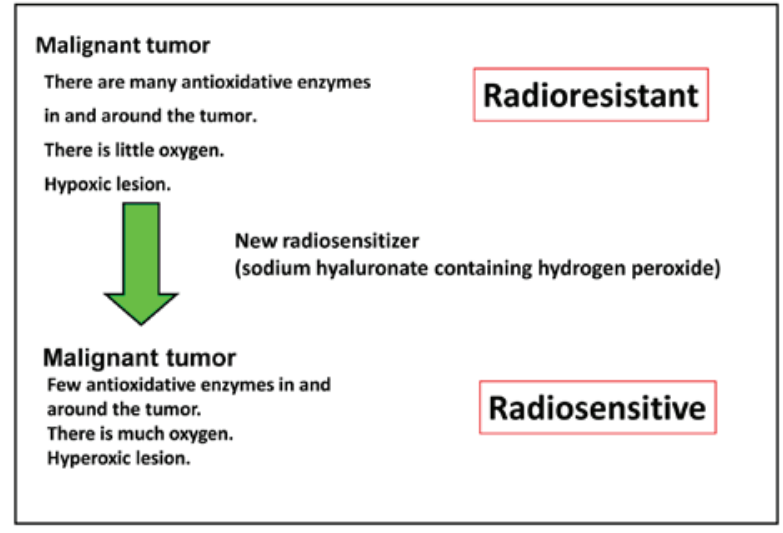

Figure 1. Concepts underlying the mechanism of action of KORTUC II, a novel enzyme-targeting radiosensitization treatment. With KORTUC II treatment, radioresistant tumors become radiosensitive. KORTUC II, Kochi Oxydol-Radiation Therapy for Unresectable Carcinomas, Type II.

was administered, whereas for other sites, various forms of irradiation (including one-field irradiation, two opposed-fields irradiation, multiple-field irradiation and intensity-modulated radiation therapy) were administered, according to the depth and location of the target lesion. Based on the radiodermatitis of the treated area, the dose of radiation was adjusted to the aforementioned number of times and exposure dose. The X-ray energy level was $4 \mathrm{MV}$, while the energy of the electron beam was selected for individual patients according to the depth of the target lesion. Injection of 3-6 ml KORTUC II (consisting of $0.83 \% \mathrm{w} / \mathrm{v}$ sodium hyaluronate and a $0.5 \% \mathrm{w} / \mathrm{v}$ solution of hydrogen peroxide) was initiated at the sixth radiation fraction, and was performed twice/week (on Mondays and Thursdays) under ultrasonographic guidance (High Vision 900; Hitachi, Ltd., Tokyo, Japan), in order to maintain a high concentration of oxygen in the tumor, since the addition of hyaluronic acid to the hydrogen peroxide solution delays the decomposition of hydrogen peroxide, which enables to maintain a high concentration of oxygen in the tumor for $>24 \mathrm{~h}$ (4-8). The injection rate of the radiosensitizer was adjusted according to the tumor size, and the total number of injections was 5-6. Patients' data and therapeutic effects of KORTUC II are described in Table I. Following radiotherapy with KORTUC II, hormonal therapy and/or chemotherapy with denosumab (Daiichi-Sankyo Co., Ltd., Tokyo, Japan), letrozole (AstraZeneca, London, UK) or taxane (Sanofi, Co., Ltd., Tokyo, Japan) was administered to the patients to prevent recurrence.

Assessment of therapeutic response. The majority of the 20 patients enrolled in the study underwent PET-CT examinations prior to and 1-7 months following KORTUC II treatment. The therapeutic effects were evaluated by comparing the results of the PET-CT examinations of the treated regions prior and subsequent to treatment. Those patients who did not undergo PET-CT examinations were examined by magnetic resonance imaging (MRI) prior and following irradiation therapy in order to evaluate the therapeutic effect of the treatment. Patients underwent PET-CT or MRI examinations every 6 months thereafter, if possible. The final therapeutic response of the lesion was assessed according to the revised Response Evaluation Criteria in Solid Tumors guidelines version 1.1 (21), 
ณ

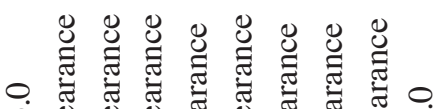

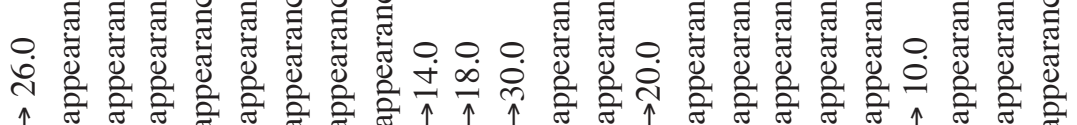

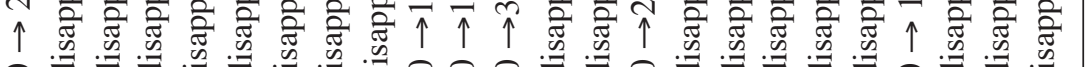

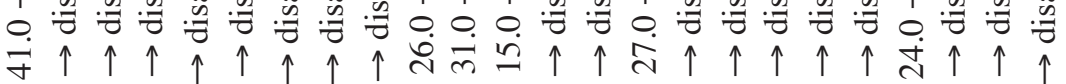

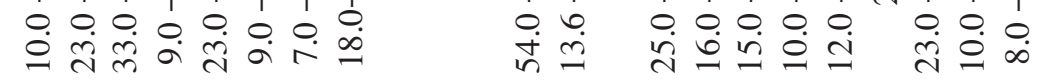

표요

焉窟

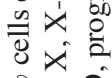

ठำ

$\hat{x} \varrho$

字产 흉

童结

bi

署

焉

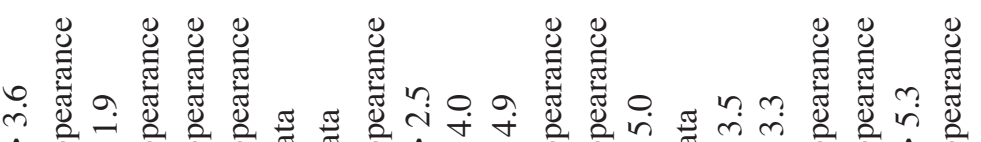

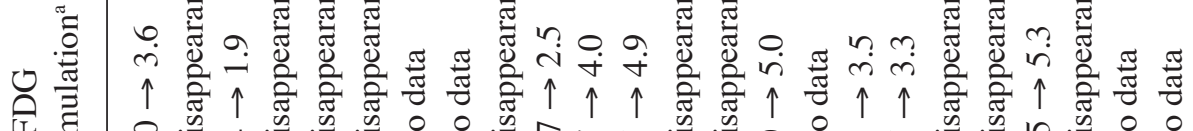

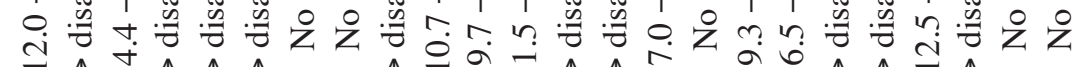

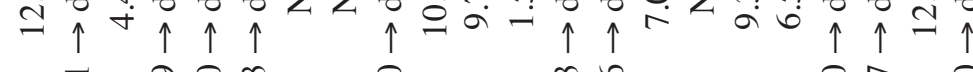

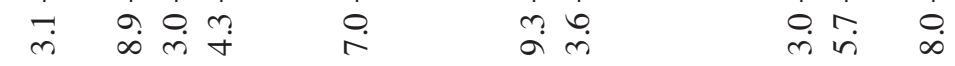

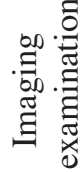

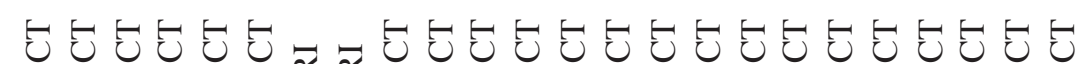

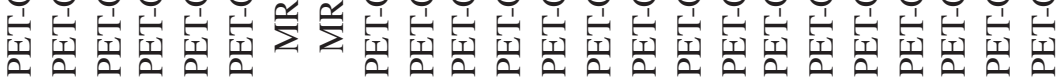

ڤ.

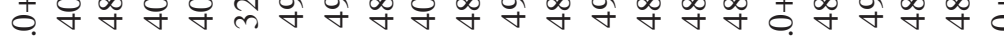

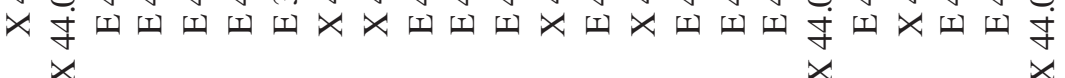

$\frac{0}{0}$
$\stackrel{\Xi}{\Xi}$

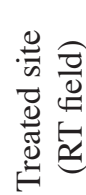

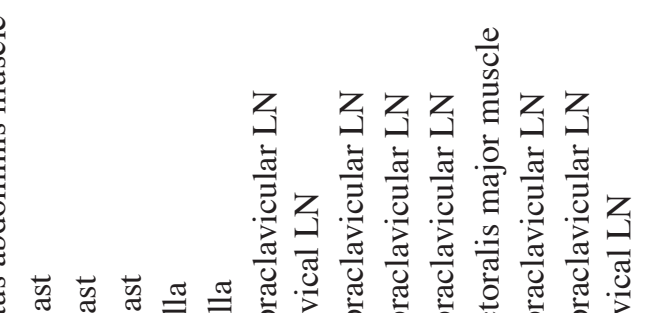

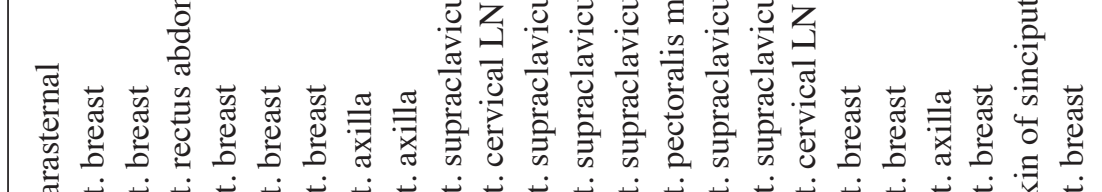

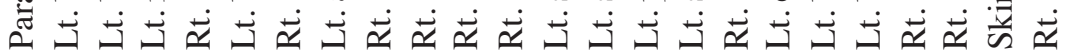

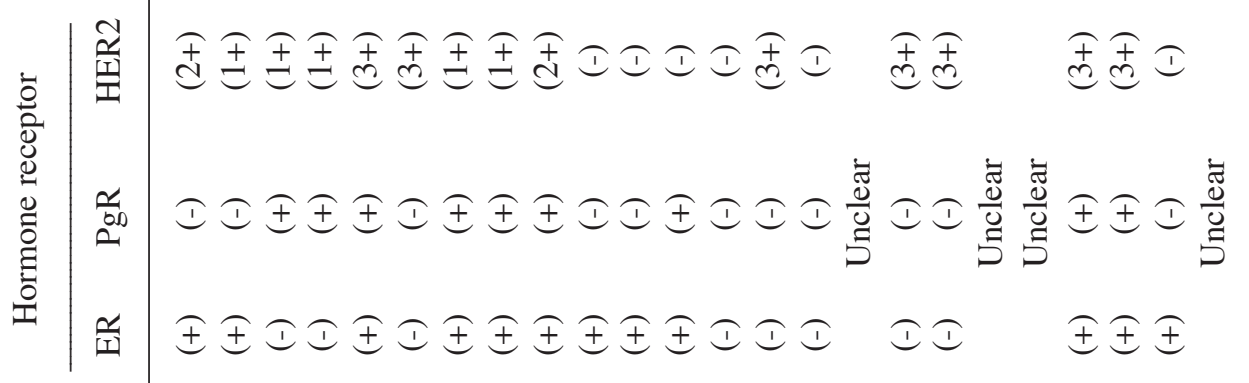
का

选造

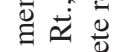

育若 
A

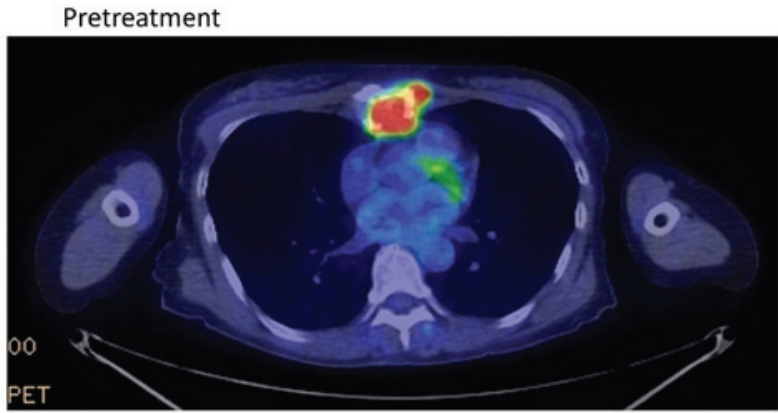

B

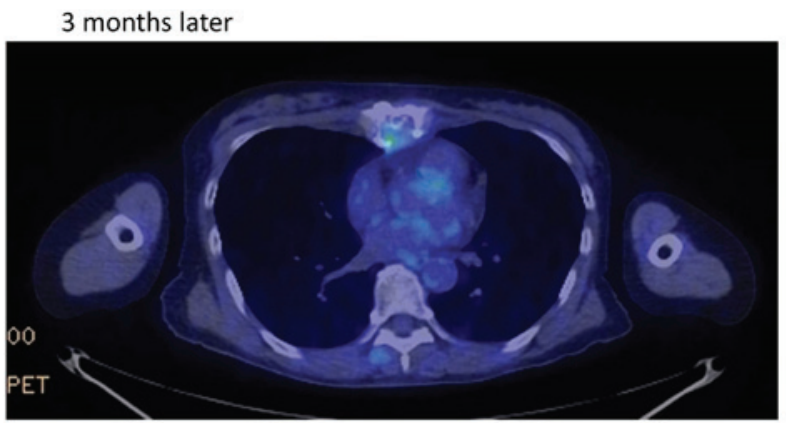

Figure 2. Therapeutic response of patient 1 in Table I, a 61-year-old woman with recurrent breast cancer at the sternum, as evaluated by positron emission tomography-CT examination (A) prior to and (B) 3 months following treatment with Kochi Oxydol-Radiation Therapy for Unresectable Carcinomas, Type II. The maximum standardized uptake value of fluorodeoxyglucose accumulation at the sternum decreased from 12.0 to 3.6. The minor axis of the target lesion decreased from 41.0 to $26.0 \mathrm{~mm}$ on CT. The therapeutic effect was assessed as partial response. CT, computed tomography; PET, positron emission tomography.

A Pretreatment

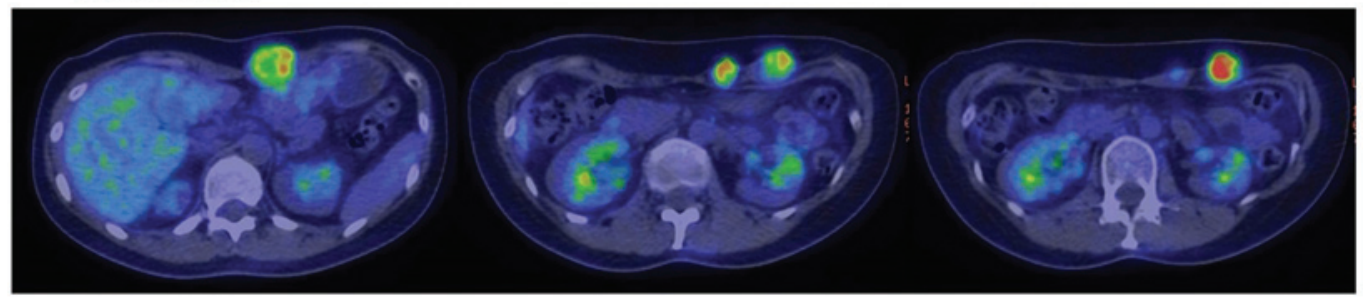

B

4 months later

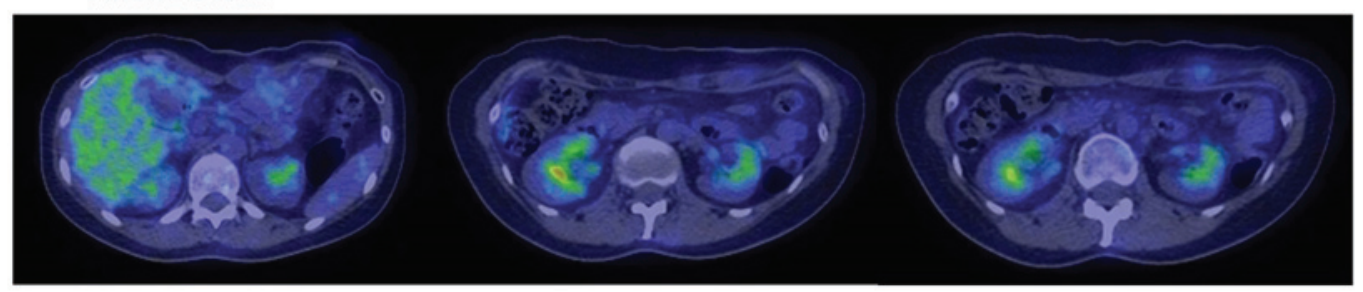

Figure 3. Therapeutic response of patient 3 in Table I, a 46-year-old woman with recurrent breast cancer at the left rectus abdominis muscle, as evaluated by positron emission tomography-CT examination (A) prior to and (B) 4 months following treatment with Kochi Oxydol-Radiation Therapy for Unresectable Carcinomas, Type II. The left, centre and right panels show the upper, middle and lower sections of the abdomen, respectively. The maximum standardized uptake value of fluorodeoxyglucose accumulation at the left rectus abdominis muscle decreased from 8.9 to unmeasurable. The minor axis of the largest target lesion decreased from $33.0 \mathrm{~mm}$ to unmeasurable on CT. The therapeutic effect was assessed as complete response. Following treatment, no obvious recurrences were observed at the treated site. CT, computed tomography.

A

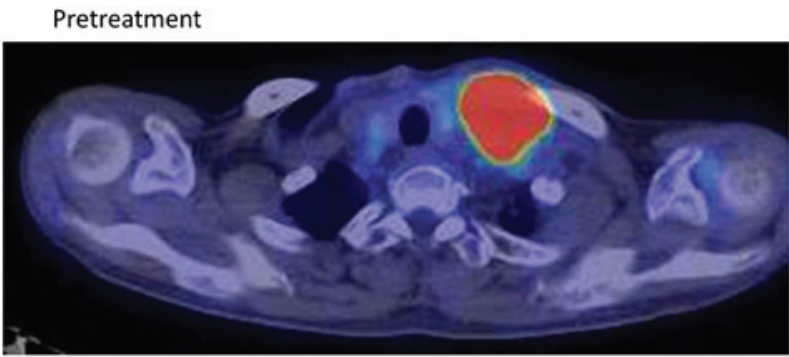

B 2 months later

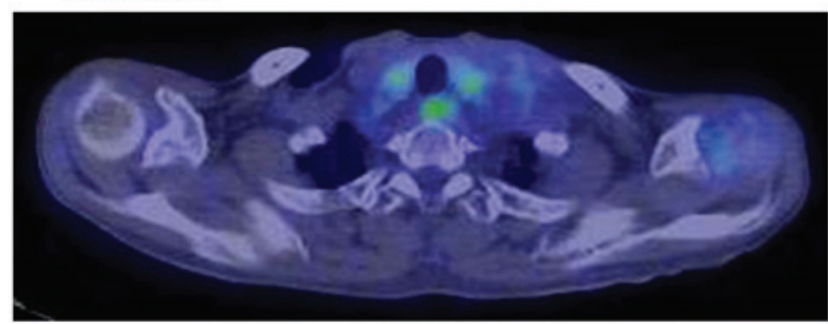

Figure 4. Therapeutic response of patient 11 in Table I, a 69-year-old woman with recurrent breast cancer at the left supraclavicular lymph node, as evaluated by positron emission tomography-CT examination (A) prior to and (B) 2 months following treatment with Kochi Oxydol-Radiation Therapy for Unresectable Carcinomas, Type II. Following treatment, the maximum standardized uptake value of fluorodeoxyglucose accumulation at the left supraclavicular lymph node decreased from 9.3 to unmeasurable, and the minor axis of the target lesion decreased from $54.0 \mathrm{~mm}$ to unmeasurable on CT. The therapeutic effect was assessed as complete response. No obvious recurrences were observed at the treated site following treatment. CT, computed tomography.

and patient monitoring and tumor assessment were performed monthly. Treatment-associated complications were assessed in detail to evaluate the feasibility of the KORTUC II approach, according to the Common Terminology Criteria for Adverse Events [CTCAE; version 4.0 (22)]. Patients were followed-up for $\geq 15$ months. 
Formulation example. A $2.5-\mathrm{ml}$ syringe of hyaluronic acid preparation (Kaken Pharmaceutical Co., Ltd., Tokyo, Japan) with a $1 \% \mathrm{w} / \mathrm{v}$ concentration of sodium hyaluronate (ARTZ Dispo ${ }^{\circledR}$; Seikagaku Corporation, Tokyo, Japan) was used, which contained $25.0 \mathrm{mg}$ sodium hyaluronate, $2.5 \mathrm{mg}$ L-methionine, sodium chloride, potassium phosphate, crystalline sodium dihydrogen phosphate and an isotonizing agent. The preparation was a colorless, transparent, viscous, aqueous solution with a $\mathrm{pH}$ of 6.8-7.8, a specific osmotic pressure of 1.0-1.2 (relative to physiological saline) and an average molecular weight of 600,000-1.2 million Da. To prepare the final radiosensitizer solution, $0.5 \mathrm{ml}$ of a $3 \% \mathrm{w} / \mathrm{v}$ solution of hydrogen peroxide (Oxydol; Ken-ei Pharmaceutical Co. Ltd., Osaka, Japan) was added immediately prior to use, and the solution was mixed well. This final radiosensitizer preparation had a concentration of sodium hyaluronate and hydrogen peroxide of 0.83 and $\sim 0.50 \%$, respectively. The constituents of the radiosensitizer were the same as those used previously for the treatment of chemotherapy-resistant supraclavicular lymph node metastases (7).

\section{Results}

The treatment was well tolerated with minimal adverse effects, since 18 patients (90\%) exhibited local pain or flare at the injection site, 1 patient $(5 \%)$ experienced soreness and hair loss at the treated part, and 1 patient (5\%) presented worsening of edema as an acute phase complication. All patients were cured by local treatment, and evaluated as displaying grade I complications, according to the CTCAE criteria version 4.0. One patient $(5 \%)$ also exhibited tumor collapse fever (an acute systemic syndrome caused by abundant cancer cell death following chemo- or radiotherapy) that resolved with symptomatic treatment (fluid therapy and antibiotic medication), and was evaluated as presenting grade II complications, according to the aforementioned CTCAE criteria. No patients displayed chronic phase complications.

Of the 24 lesions, 18 (75\%) exhibited complete response, $5(21 \%)$ exhibited partial response, $0(0 \%)$ exhibited stable disease and 1 (4\%) exhibited progressive disease. The response rate was $96 \%$. The overall survival rate was $100 \%$ at 1 year and $95 \%$ at 2 years, since 19 out of 20 patients survived for 2 years following treatment. No obvious recurrences were observed at the treated sites.

The treatment outcomes were satisfactory, and the adverse events were within the acceptable range. Representative PET-CT and MRI examinations are depicted in Figs. 2-4. The mean follow-up period was 51 months, and the disease-free survival was 28 months at the end of June 2014. At the time of writing, 16 patients were alive.

\section{Discussion}

Improved diagnostic methods have resulted in earlier detection of recurrent tumors and/or distant metastases when they are limited to a single site/organ (oligometastasis) (1-3). For these cases, radiotherapy is considered to be a reliable method of treatment (1-3). Previous studies have indicated that re-irradiation plus hyperthermia for recurrent breast cancer may be more effective than radiotherapy alone (23-25). Oldenborg et al (23) reported that, with re-irradiation plus hyperthermia, the 3-year survival rate was $66 \%$, and the 3 and 5 -year local control rates were 78 and 65\%, respectively, in patients with high-risk recurrent breast cancer. Thus, the therapeutic effect of re-irradiation plus hyperthermia was observed to be better than radiotherapy alone, which was confirmed by further studies $(24,25)$.

Despite the differences in the evaluation method and timing, the therapeutic effect of KORTUC II in the present study was equally excellent to that of re-irradiation plus hyperthermia. Furthermore, KORTUC II is administered more easily than re-irradiation plus hyperthermia. In the present study, the response rate (96\%) and the overall survival rates at $1(100 \%)$ and 2 years (95\%) observed for KORTUC II treatment were considered satisfactory. Therefore, KORTUC II may constitute an excellent therapeutic approach for cancer patients. The present authors hypothesize that the majority of patients with oligometastasis and local recurrence may achieve complete remission by combining radiotherapy with KORTUC II.

Using animal models, Tokuhiro et al (8) identified that sodium hyaluronate was the most effective supporting agent for hydrogen peroxide in maintaining a high concentration of oxygen in tumor tissues. KORTUC II consists of $0.83 \%$ $\mathrm{w} / \mathrm{v}$ sodium hyaluronate and a $0.5 \% \mathrm{w} / \mathrm{v}$ solution of hydrogen peroxide, which are inexpensive and widely available reagents (4-8). Thus, the novel radiosensitizer KORTUC II could be used for the treatment of local cancer worldwide. Regarding the use of this agent, it is essential to avoid its direct injection into blood vessels, and to confirm an even distribution of oxygen microbubbles throughout the tumor tissue under ultrasonographic or CT guidance (4-7).

In conclusion, the treatment of recurrent breast cancer with radiotherapy and KORTUC II in the present study was well tolerated with minimal adverse effects. At present, the treatment outcomes for this agent are satisfactory, and the adverse events are within the acceptable range. In addition, the cost of this type of therapy is much lower than that of the molecular-targeted therapies currently used for the treatment of recurrent breast cancer, such as cetuximab (20). However, both the number of patients treated with KORTUC II thus far and the follow-up period are insufficient to draw definitive conclusions. Therefore, well-designed, prospective, randomized, clinical trials are required to establish the therapeutic efficacy of KORTUC II.

\section{Acknowledgements}

The present study was partially supported by a Grant-in-Aid for Scientific Research from the Japanese Ministry of Education, Culture, Sports, Science and Technology (Tokyo, Japan; no. 25461916)

\section{References}

1. Niibe Y, Kuranami M, Matsunaga K, Takaya M, Kakita S, Hara T, Sekiguchi K, Watanabe M and Hayakawa K: Value of high-dose radiation therapy for isolated osseous metastasis in breast cancer in terms of oligo-recurrence. Anticancer Res 28: 3929-3931, 2008.

2. Milano MT, Zhang H, Metcalfe SK, Muhs AG and Okunieff P: Oligometastatic breast cancer treated with curative-intent stereotactic body radiation therapy. Breast Cancer Res Treat 115: 601-608, 2009. 
3. Niibe Y and Hayakawa K: Oligometastases and oligo-recurrence: The new era of cancer therapy. Jpn J Clin Oncol 40: 107-111, 2010.

4. Ogawa Y: Paradigm shift in radiation biology/radiation oncology-exploitation of the " $\mathrm{H}_{2} \mathrm{O}_{2}$ effect" for radiotherapy using low-LET (linear energy transfer) radiation such as x-rays and high-energy electrons. Cancers (Basel) 8; E28, 2016.

5. Ogawa Y, Kubota K, Ue H, Kataoka Y, Tadokoro M, Miyatake K, Tsuzuki K, Yamanishi T, Itoh S, Hitomi J, et al: Phase I study of a new radiosensitizer containing hydrogen peroxide and sodium hyaluronate for topical tumor injection: A new enzyme-targeting radiosensitization treatment, Kochi Oxydol-Radiation Therapy for Unresectable Carcinomas, Type II (KORTUC II). Int J Oncol 34: 609-618, 2009.

6. Ogawa Y, Kubota K, Ue H, Tadokoro M, Matsui R, Yamanishi T, Hamada N, Kariya S, Nishioka A, Nakajima H, et al: Safety and effectiveness of a new enzyme-targeting radiosensitization treatment (KORTC II) for intratumoral injection for low-LET radioresistant tumors. Int J Oncol 39: 553-560, 2011.

7. Aoyama N, Ogawa Y, Kubota K, Ohgi K, Kataoka Y, Miyatake K, Tadokoro M, Yamanishi T, Ohnishi T, Hamada N, et al: Therapeutic response to a new enzyme-targeting radiosensitization treatment (KORTUC-SC) for patients with chemotherapy-resistant supraclavicular lymph node metastasis. J Cancer Res Ther 1: 215-219, 2013.

8. Tokuhiro S, Ogawa Y, Tsuzuki K, Akima R, Ue H, Kariya S and Nishioka A: Development of a novel enzyme-targeting radiosensitizer (KORTUC) containing hydrogen peroxide for intratumoral injection for patients with low linear energy transfer-radioresistant neoplasms. Oncol Lett 1: 1025-1028, 2010

9. Jette DC, Wiebe LI and Chapman JD: Synthesis and in vivo studies of the radiosensitizer $4-\left[{ }^{82} \mathrm{Br}\right]$ bromomisonidazole. Int J Nucl Med Biol 10: 205-210, 1983.

10. Coleman CN: Hypoxic cell radiosensitizers: Expectations and progress in drug development. Int J Radiat Oncol Biol Phys 11: 323-329, 1985

11. Lawrence TS, Blackstock AW and McGinn C: The mechanism of action of radiosensitization of conventional chemotherapeutic agents. Semin Radiat Oncol 13: 13-21, 2003.

12. Böhm L, Roos WP and Serafin AM: Inhibition of DNA repair by pentoxifylline and related methylxanthine derivatives. Toxicology 193: 153-160, 2003

13. Milas L: Cyclooxygenase-2 (COX-2) enzyme inhibitors as potential enhancers of tumor radioresponse. Semin Radiat Oncol 11: 290-299, 2001

14. Choy $\mathrm{H}$ and Milas L: Enhancing radiotherapy with cyclooxygenase-2 enzyme inhibitors: A rational advance. J Natl Cancer Inst 95: 1440-1452, 2003.
15. Overgaard J: Clinical evaluation of nitroimidazoles as modifiers of hypoxia in solid tumors. Oncol Res 6: 509-518, 1994.

16. Gerlach NL, Barkhuysen R, Kaanders JH, Janssens GO, Sterk W and Merkx MA: The effect of hyperbaric oxygen therapy on quality of life in oral and oropharyngeal cancer patients treated with radiotherapy. Int J Oral Maxillofac Surg 37: 255-259, 2008.

17. Overgaard J: Hypoxic radiosensitization: Adored and ignored. J Clin Oncol 25: 4066-4074, 2007.

18. Williamson RA: An experimental study of the use of hyperbaric oxygen to reduce the side effects of radiation treatment for malignant disease. Int J Oral Maxillofac Surg 36: 533-540, 2007.

19. Oronsky BT, Knox SJ and Scicinski J: Six degrees of separation: The oxygen effect in the development of radiosensitizers. Transl Oncol 4: 189-198, 2011

20. Wardman P: Chemical radiosensitizers for use in radiotherapy. Clin Oncol (R Coll Radiol) 19: 397-417, 2007.

21. Nishino M, Jackman DM, Hatabu H, Yeap BY, Cioffredi LA, Yap JT, Jänne PA, Johnson BE and Van den Abbeele AD: New Response Evaluation Criteria in Solid Tumors (RECIST) guidelines for advanced non-small cell lung cancer: comparison with original RECIST and impact on assessment of tumor response to targeted therapy. AJR Am J Roentgenol 195: 221-228, 2010.

22. Bennett AV, Dueck AC, Mitchell SA, Mendoza TR, Reeve BB, Atkinson TM, Castro KM, Denicoff A, Rogak LJ, Harness JK et al; National Cancer Institute PRO-CTCAE Study Group: Mode equivalence and acceptability of tablet computer-, interactive voice response system-, and paper-based administration of the U.S. National Cancer Institute's Patient-Reported Outcomes version of the Common Terminology Criteria for Adverse Events (PRO-CTCAE). Health Qual Life Outcomes 14: 24, 2016.

23. Oldenborg S, Van Os RM, Van rij CM, Crezee J, Van de Kamer JB Rutgers EJ, Geijsen ED, Zum vörde sive vörding PJ, Koning CC and Van tienhoven G: Elective re-irradiation and hyperthermia following resection of persistent locoregional recurrent breast cancer: A retrospective study. Int J Hyperthermia 26: 136-144, 2010.

24. Ben-Yosef R, Vigler N, Inbar M and Vexler A: Hyperthermia combined with radiation therapy in the treatment of local recurrent breast cancer. Isr Med Assoc J 6: 392-395, 2004.

25. Zagar TM, Oleson JR, Vujaskovic Z, Dewhirst MW, Craciunescu OI, Blackwell KL, Prosnitz LR and Jones EL: Hyperthermia combined with radiation therapy for superficial breast cancer and chest wall recurrence: A review of the randomised data. Int J Hyperthermia 26: 612-617, 2010. 